\title{
Psychotropic Medications-Induced Tardive Dyskinesia and Associated Factors Among Patients with Mental Illness in Ethiopia
}

This article was published in the following Dove Press journal: Clinical Pharmacology: Advances and Applications

\section{Assefa Kumsa \\ Shimelis Girma (D) \\ Bezaye Alemu \\ Liyew Agenagnew (iD)}

Department of Psychiatry, Faculty of Medical Science, Institute of Health, Jimma University, Jimma, Ethiopia
Correspondence: Liyew Agenagnew Jimma University, 378, Jimma, Ethiopia Tel +25l 9|2806976

Email liyew2003@gmail.com
Background: Tardive dyskinesia (TD) remains a significant burden especially among patients taking psychotropic medications, and it is associated with adverse effects that can lead to subjective suffering, stigma, poor compliance to medication, and poor quality of life. However, it is unrecognized and overlooked in clinical settings. So, this study aimed to assess the magnitude of tardive dyskinesia and associated factors among mentally ill patients attending follow-up treatment at Jimma University Medical Center Psychiatry clinic, Jimma, Southwest Ethiopia, 2019.

Methods: Institutional-based cross-sectional study design was conducted in 417 samples. Participants were selected by systematic random sampling techniques. Data were collected by a semi-structured interviewer-administered questionnaire, and the document was reviewed to obtain the patient's profile. Tardive dyskinesia was assessed by using the Extrapyramidal Symptom Rating Scale after informed consent was obtained from respondents. Data entry was done by EpiData version 3.1, and analysis was done by using SPSS 22.0 statistical software. Binary logistic regression and multivariate logistic regression were used to see the association and to identify independent factors at a p-value of $<0.05$.

Results: Prevalence of drug-induced tardive dyskinesia was 15.4\% (CI 95\%: 12.0, 19.3). Female, age range between 30 and 44 years, having a diagnosis of major depressive disorder with the psychotic feature, taking chlorpromazine equivalent dose $>600 \mathrm{mg}$, and taking anticholinergic medications were variables positively associated with tardive dyskinesia, whereas cigarette smoking was negatively associated with tardive dyskinesia.

Conclusion: The prevalence of drug-induced tardive dyskinesia in this study was high. Prescribing medications less than $600 \mathrm{mg}$ equivalent dose of chlorpromazine, giving attention for female patients, patients having a diagnosis of major depressive disorder, and reducing giving anticholinergic medications will be important measures for clinicians to reduce the occurrence of tardive dyskinesia.

Keywords: mental illness, antipsychotics, tardive dyskinesia, Jimma

\section{Introduction}

Following the introduction of antipsychotic medications in 1952, drug-induced movement disorders (DIMDs) emerged as a complication of treatment. To date, drug-induced movement disorders remain a major concern in treatment with antipsychotic medication. ${ }^{1}$

Psychotropic-induced movement disorders can be classified based on the onset of symptoms as acute which appear within hours to days, sub-acute which occur after days to weeks after starting antipsychotic or increasing the dosage which 
includes Dystonia, Parkinsonism, and Akathisia, ${ }^{2}$ and chronic which occurs after months spent in exposure to the antipsychotic medications, includes Tardive Dystonia and Tardive Dyskinesia. ${ }^{3}$

\section{Tardive Dyskinesia}

The burden of drug-induced movement disorder according to the Diagnostic and Statistical Manual of Mental Disorders, fourth edition (DSM-IV) criteria was $61.6 \%{ }^{4}$

A study conducted among schizophrenic patients residing in the southern region of Israel has shown that between $29 \%$ and $74 \%$ of the patients experienced one form of movement disorder. ${ }^{5}$ Similar to this, a study from Netherland among patients with chronic severe mental illness showed $68 \%$ of the participants had at least one type of persistent movement disorder and $24.7 \%$ had at least 2 types of persistent movement disorder. ${ }^{6}$

According to a study done in central Estonia to assess DIMDs in a naturalistic schizophrenia population that uses conventional neuroleptics, the prevalence of drug-induced TD was $32.3 \%{ }^{7}$

In a study done in South Africa subjects who had been exposed to typical antipsychotic drugs for at least 6 months and were screened for abnormal movements using the Abnormal Involuntary Movement rating Scale (AIMS), 29 patients (28.4\%) met the criteria for a positive AIMS. ${ }^{8}$

In Ethiopia, the study done among psychotic patients revealed that the magnitude of psychotropic medicationsinduced movement disorders was $56 \%{ }^{9}$

Studies also indicate that up to $50 \%$ of all patients treated with some antipsychotic medications for mental illness will develop drug-induced Tardive Dyskinesia. ${ }^{10}$

The prevalence of drug-induced TD accounts for $25 \%$ in the study from Canada, ${ }^{11} 28.4 \%$ from Netherland, ${ }^{6}$ from California $63 \%{ }^{12}$ from Poland $(11.9 \%),{ }^{13}$ in France $(1.4 \%),{ }^{14} 26.4 \%$ finding from India, ${ }^{15}$ in Serbia $24 \%$ to $30 \%{ }^{16}$ and $5.9 \%$ as the finding from Saudi Arabia. ${ }^{17}$

A study done in Kenya among 164 psychiatric outpatients at Mathari Hospital indicates that the prevalence of drug-induced TD was $11.9 \%{ }^{18}$ whereas the prevalence of drug-induced TD in University of Port Harcourt Teaching Hospital, Nigeria was $(5.8 \%)^{19}$ and from a crosssectional study done on 377 psychotic patients in Ethiopia, 2014, using AIMS reveals that the prevalence of psychotropic medications-induced TD was $45(11.9 \%){ }^{9}$

Being old age, being female, brain damage, use of a high dose of antipsychotics, use of more than $400 \mathrm{mg} /$ day on the equivalent dose of chlorpromazine, long duration of exposure, presence of drug-induced parkinsonism in the early phase of neuroleptics use, use of anticholinergic drugs and anti-parkinsonism drugs, intermittent neuroleptics treatment, use of conventional antipsychotics, primary Psychiatric diagnosis of affective disorder and substance including alcohol and having comorbid medical illness were most commonly mentioned factors associated with Tardive Dyskinesia. ${ }^{7,9,11-14,20,21}$

The presence of TD results in social stigmatization, worsen stigma associated with treatment for mental illness, physical disabilities, poorer quality of life, noncompliance which results in relapse, difficulty in social functioning and impair the patient's activities of daily living ${ }^{22-24}$ and had a serious burden on family and in the community. ${ }^{10}$ Despite this, the magnitude of TD and associated factors in Ethiopia were not well addressed especially in the study area and previous studies conducted on patients with psychotic disorder mainly on schizophrenic patients and who have taken typical antipsychotics medications, but in this study, we conducted in all mentally ill patients who have taking any type of antipsychotic medications so this study is aimed to determine the prevalence of psychotropicinduced TD and associated factors among mentally ill patients attending follow-up treatment at Jimma University Medical Center, psychiatry clinic and this will help the clinicians to be aware of these side effects and to make a good clinical judgment in their routine clinical activity when they prescribe antipsychotic medications.

\section{Methods and Materials Study Setting}

The study was conducted in Jimma University Medical Center (JUMC) psychiatry clinic from April 01 to June 05/2019. Jimma University Medical Center is one of the oldest governmental hospitals, which was established in 1937. It renders service including inpatient and outpatients for about 15 million populations in southwest Ethiopia including Psychiatric service which established in 1996 next to Amanuel mental health specialized hospital, and currently, there are around 1000 psychiatric patients per month who are taking antipsychotic medications and attending follow-up treatment, on average around 50 patients were visiting in daily bases.

\section{Study Design}

An institutional-based cross-sectional study design was employed. 


\section{Populations}

All mentally ill patients attending follow-up treatment at JUMC psychiatric clinic in 2019 were source populations whereas, mentally ill patients attending follow-up treatment at a psychiatric clinic and taking antipsychotic medications during the study period were the study populations.

\section{Inclusion and Exclusion Criteria}

Mentally ill Patients attending follow-up treatment at the psychiatric outpatient department and who had been on antipsychotic medications were included in the study; on the other hand, mentally ill patients who were acutely ill and unable to give the required information were excluded from the study.

\section{Sample Size Determination}

The minimum sample size determination formula used is

$(n)=\frac{\left(\frac{Z \alpha}{2}\right)^{2} P(1-P)}{d^{2}}$, where

$\mathrm{n}=$ minimum sample size required for the study.

$Z=$ the reliability coefficient corresponding to $95 \%$ confidence level $(Z=1.96)$.

$\mathrm{P}=56 \%$ for overall drug-induced movement disorders which was taken from the study conducted at Amanuel Specialized Mental Hospital, Ethiopia. ${ }^{9}$

$\mathrm{d}=$ Absolute precision or tolerable margin of error (d) $=5 \%=0.05$.

Considering a $10 \%$ non-response rate, the total sample size was 417 .

\section{Sampling Techniques}

A systematic random sampling technique was used to select the study participants. The average number of mentally ill patients attending follow-up treatment at JUMC psychiatric clinic and who had been on antipsychotic medications per month was around 1000 .

The sample size required for this study was 417 , so, the sampling fraction was; $\mathrm{k}=\mathrm{N} / \mathrm{n}=1000 / 417=2.39 \sim 2$. Therefore, participants who were taking antipsychotic medications selected every two intervals of patients visiting, the first participant was selected by the lottery method. The card of the patients was coded and circulate to all data collectors to avoid redundancy.

\section{Data Collection Procedures and Instruments}

Data were collected using face-to-face interviews by using semi-structured and pre-tested interviewer-administered questionnaires, medical chart review, and examination of the patients.

Four BSc psychiatric nurses participated in data collection and two mental health professionals supervised the overall data collection process.

Interviewer-administered questionnaires used which has six sections a socio-demographic section to assess the patients' background information, medicationrelated factors, and clinical factors were assessed by yes/no answers of respondents and by using chart review moreover substance-related factors were assessed by using some factors adopted from ASSIST WHO, V3.1. ${ }^{25}$

The extrapyramidal symptom rating scale (ESRS) was used to assess the presence of drug-induced tardive dyskinesia. ${ }^{26}$ Studies found high inter-rater reliability correlations and for inter-rater reliability of raters $>$ or $=80 \%$ of the item ratings of the complete scale. During a cross-scale comparison, there was a $96 \%$ agreement between AIMS and ESRS with DSM-IV TR criteria. In this study, Cronbach's alpha of ESRS was found to be $78.9 \%$.

The score for TD ranges from 0 to 42 based on the sum of all 7 items in the TD objective examination. The presence of TD measured by a score of 3 or greater on at least in one item or a score of 2 on two items is required.

Clinical Global Impression Severity (CGI-S) scales used to assess symptom severity which rated according to results of the subjective questionnaire, examination subscales, and the evaluator's clinical experience by applying an 8 point rating $(0:=$ absent; $1=$ borderline; 2 : $=$ very mild; $3=$ mild; $4:=$ moderate; $5=$ moderately severe; $6=$ marked; $7=$ severe; $8=$ extremely severe).

\section{Data Quality Control}

The questionnaires were translated into local languages (Amharic/Afan Oromo) and back-translated to English to check the consistency and understandability of the tool. Two days of training was given for data collectors and supervisors on the data collection tool and sampling methods. The questionnaire was pretested before the actual data collection on $5 \%$ of the sample size at Shenen Gibe General Hospital, and the questionnaires were checked for their clarity, simplicity, and understandability.

During data collection, the questionnaire was checked for its completeness on daily basis by supervisors and investigators. 


\section{Data Processing and Analysis}

The data were edited, cleaned, coded, and entered into EpiData version 3.1 and analyzed by using SPSS version 22. Binary Logistic regression was used to identify the candidate variables for the multivariate logistic regression at a p-value less than 0.25 and multivariate logistic regression analysis was done to identify statistically significant variables at a p-value less than 0.05 . The strength of the association was presented by the odds ratio with a $95 \%$ confidence interval.

Multicollinearity was checked by a variance inflation factor (VIF) and Hosmer-Lemeshow goodness was used to check model fitness. Results were presented in the form of tables and figures using frequency and summary statistics such as mean, percentage to describe the study population in relation to different variables.

\section{Ethical Considerations}

Ethical clearance was obtained from the Ethical Review Board of Jimma University Institute of Health. The data collectors were clearly explaining the aims of the study for study participants and written informed consent was obtained from each study participant besides a parent or legal guardian provided informed consent for participants under the age of 18 years, and that this study was conducted in accordance with the Declaration of Helsinki. Participants had the right to refuse or discontinue the interview at any time. Privacy and confidentiality were kept. Participants who suffer from side effects were linked to professionals for further evaluation and treatment.

\section{Results}

\section{General Descriptions of Study Participants}

A total of 410 patients responded to the questionnaires, which gives a response rate of $98.3 \%$. The mean age of the respondents was 33.3 years with $\mathrm{SD} \pm 8.55$ years. About $263(64.1 \%)$ of the study participants were male and 213 (52\%) of the study participants were single. The majority of $237(58.7 \%)$ of the study participants were Oromo by ethnicity, and 218 (53.2\%) were jobless by their occupation (Table 1).

\section{Clinical-Related Characteristics of Study Participants}

Most of the study participants 223 (54.4\%) had the diagnosis of schizophrenia. Moreover, the majority of the study participants $246(60.0 \%)$ had received treatment with a mean duration of 4.8 years and $(\mathrm{SD} \pm 3.9)$ within the range of $1-5$ years and $38(9.3 \%)$ of participants had a history of physical illness (Table 2).

\section{Medication-Related Characteristics of the Study Participants}

Out of all study participants, 240 (58.5\%) were receiving typical antipsychotic medications, whereas 95 (23.2\%) were receiving atypical antipsychotic medications and 75 (18.3\%) were receiving both typical and atypical antipsychotic medications. The mean daily chlorpromazine equivalent dose was $425 \mathrm{mg}$ with $\mathrm{SD} \pm 245$.

Nearly half of the respondents 187 (45.6\%) received anticholinergic drugs in combination with antipsychotic medications, whereas around one-fifth of respondents 75 $(18.3 \%)$ received mood stabilizers in combination with antipsychotic medications. TD was present in 33 (52.4\%) patients using typical antipsychotics (Table 3).

Most of the study participants received chlorpromazine followed by risperidone compared to other antipsychotic medications (Figure 1).

\section{Substance-Related Characteristics of Study Participants}

Of all respondents, 164 (39.9\%) had used substances at least once in their lifetime and 99 (24.1\%) were using substances in the last 3 months before the study period (Figure 2).

\section{Prevalence of Psychotropic Medications-Induced TD}

The prevalence of psychotropic medications-induced TD was $63(15.4 \%, 95 \%$ CI: 12.0, 19.3).

Jaw movement $66(16.1 \%)$ and upper extremity movement $52(12.7 \%)$ were the most prevalent signs of TD (Table 4).

\section{Factors Associated with Tardive Dyskinesia}

In the bivariate logistic regression analysis, variables such as sex, age, educational level, diagnosis, type and dose of antipsychotics, medication for movement disorder, medication adherence, khat, and tobacco use were candidate variables for the multivariate logistic regression analysis at a p-value less than 0.25 . 
Table I Socio-Demographic Characteristic of Mentally III Patients Attending Follow-Up Treatment at JUMC Psychiatry Clinic, 2019

\begin{tabular}{|c|c|c|c|}
\hline Variables & Categories & $\begin{array}{l}\text { Frequency } \\
(\mathrm{N}=4 \mid 0)\end{array}$ & $\begin{array}{l}\text { Percentage } \\
\text { (\%) }\end{array}$ \\
\hline \multirow[t]{3}{*}{ Age (years) } & $15-29$ & 145 & 35.4 \\
\hline & $30-44$ & 201 & 49.0 \\
\hline & $>45$ & 64 & 15.6 \\
\hline \multirow[t]{2}{*}{ Sex } & Male & 263 & 64.1 \\
\hline & Female & 147 & 35.9 \\
\hline \multirow[t]{4}{*}{ Marital status } & Married & 168 & 41 \\
\hline & Single & 213 & 52 \\
\hline & Divorced & 28 & 6.8 \\
\hline & Widowed & I & 0.2 \\
\hline \multirow[t]{4}{*}{ Religion } & Muslim & 222 & 54.1 \\
\hline & Orthodox & 120 & 29.3 \\
\hline & Protestant & 67 & 16.3 \\
\hline & Others & I & 0.2 \\
\hline \multirow[t]{5}{*}{ Ethnicity } & Oromo & 237 & 57.8 \\
\hline & Amhara & 107 & 26.1 \\
\hline & Tigre & 12 & 2.9 \\
\hline & Dawuro & 39 & 9.5 \\
\hline & Others & 15 & 3.6 \\
\hline \multirow[t]{2}{*}{ Residence } & Rural & 204 & 49.8 \\
\hline & Urban & 206 & 50.2 \\
\hline \multirow[t]{5}{*}{$\begin{array}{l}\text { Educational } \\
\text { status }\end{array}$} & $\begin{array}{l}\text { Cannot read } \\
\text { and write }\end{array}$ & & 22.0 \\
\hline & I-4 grade & 126 & 30.7 \\
\hline & $5-8$ grade & 109 & 26.6 \\
\hline & $9-12$ grade & 52 & 12.7 \\
\hline & $\begin{array}{l}\text { College and } \\
\text { above }\end{array}$ & 33 & 8.0 \\
\hline \multirow{2}{*}{$\begin{array}{l}\text { Occupational } \\
\text { status }\end{array}$} & With job & 192 & 46.8 \\
\hline & Jobless & 218 & 53.2 \\
\hline
\end{tabular}

Notes: Other religion; Catholic, Wokeffata, other ethnicities; Silte, Wolayta, Yem.

During multivariate logistic regression analysis variables such as being female, age, having a diagnosis of major depressive disorder with the psychotic feature, chlorpromazine equivalent dose $>600 \mathrm{mg}$, anticholinergic medication use, and tobacco use were significantly associated with TD at p-value less than 0.05 .

Female patients were 3.7 times $(\mathrm{AOR}=3.74,95 \% \mathrm{CI}$ : $1.56,8.9)$ more likely to develop antipsychotic-induced TD than male patients. The odds of developing antipsychotic-induced TD among patients aged range between 30 and 44 years were 1.4 times $(\mathrm{AOR}=1.41,95 \% \mathrm{CI}: 1.12$, 3.36) and $\geq 45$ years were 2.5 times $(\mathrm{AOR}=2.51,95 \% \mathrm{CI}$ :

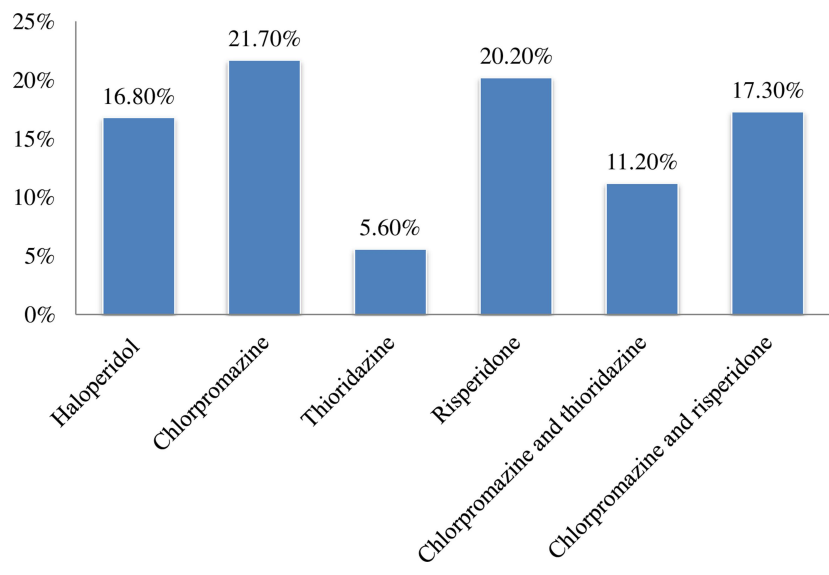

Figure I Distribution of type of antipsychotic medications received by patients with mental illness attending follow-up treatment at JUMC, 2019.

$1.79,5.42)$ higher as compared to those age range between 15 and 29 years.

Patients diagnosed with major depressive disorder with psychotic features were 2.3 times $(\mathrm{AOR}=2.3,94 \%$ CI: $1.21,9.3)$ more likely to develop antipsychoticinduced TD as compared to schizophrenic patients.

Table 2 Clinical Characteristics of Mentally III Patients Attending Follow-Up Treatment at JUMC Psychiatry Clinic, 2019

\begin{tabular}{|c|c|c|c|c|}
\hline \multirow[t]{2}{*}{ Characteristics } & \multirow{2}{*}{$\begin{array}{l}\text { Frequency } \\
(\mathrm{N}=4 \mid 0)\end{array}$} & \multirow{2}{*}{$\begin{array}{l}\text { Percent } \\
\text { (\%) }\end{array}$} & \multicolumn{2}{|l|}{ TD } \\
\hline & & & Yes & No \\
\hline \multicolumn{5}{|l|}{ Diagnosis } \\
\hline Schizophrenia & 223 & 54.4 & 91 & 132 \\
\hline $\begin{array}{l}\text { Major depressive } \\
\text { disorder with psychotic } \\
\text { feature }\end{array}$ & 99 & 24.1 & 30 & 69 \\
\hline $\begin{array}{l}\text { Bipolar I disorder with } \\
\text { psychotic feature }\end{array}$ & 74 & 18.0 & 45 & 29 \\
\hline $\begin{array}{l}\text { Other schizophrenia } \\
\text { spectrum disorder }\end{array}$ & 14 & 3.4 & 2 & 12 \\
\hline \multicolumn{5}{|l|}{ Duration of treatment } \\
\hline$<$ I years & 37 & 9.0 & 10 & 27 \\
\hline I-5 yyears & 246 & 60.0 & 85 & 161 \\
\hline$>5$ years & 127 & 31.0 & 72 & 55 \\
\hline \multicolumn{5}{|l|}{$\begin{array}{l}\text { Comorbid psychiatric } \\
\text { diagnosis }\end{array}$} \\
\hline Yes & 03 & 0.7 & 3 & 0 \\
\hline No & 407 & 99.3 & 164 & 243 \\
\hline \multicolumn{5}{|l|}{ Physical illness } \\
\hline Yes & 38 & 9.3 & 35 & 3 \\
\hline No & 372 & 90.7 & 167 & 205 \\
\hline
\end{tabular}

Notes: Other schizophrenia spectrum disorders: brief psychotic disorder, Schizophreniform disorder, delusional disorder, substance-induced psychotic disorder, psychotic disorder due to other medical condition. 
Table 3 Medication-Related Characteristics of Patients with Mental Illness Attending Follow-UP Treatment at JUMC Psychiatry Clinic, 2019

\begin{tabular}{|l|l|l|l|l|}
\hline Characteristics & Frequency & Percent & \multicolumn{2}{|l|}{ TD } \\
\cline { 3 - 5 } & & $(\%)$ & \multicolumn{2}{|l|}{} \\
\cline { 4 - 6 } & & & Yes & No \\
\hline Types of antipsychotics & & 58.5 & 33 & 207 \\
Typical & 240 & 23.2 & 8 & 87 \\
Atypical & 95 & 18.3 & 22 & 53 \\
Both & 75 & & & \\
\hline Dose of antipsychotics & & & & \\
(mg) & & 34.9 & 11 & 132 \\
<200 & 143 & 64.1 & 50 & 213 \\
200-600 & 263 & 1.0 & 4 & 0 \\
$>600$ & 4 & 18.3 & 7 & 68 \\
Mood stabilizers & 75 & 15.6 & 24 & 42 \\
Antidepressants & 66 & 6.8 & 10 & 18 \\
Benzodiazepines & 28 & & & \\
\hline Anticholinergic & & 9.0 & 19 & 18 \\
medication use & & 45.6 & 136 & 51 \\
Yes & 187 & 54.4 & 31 & 192 \\
No & 223 & & & \\
\hline Medication adherence & & 91.1 & 44 & 329 \\
Yes & 373 & & & \\
No & & & & \\
\hline
\end{tabular}

Those patients taking chlorpromazine equivalent dose $>600 \mathrm{mg}$ were 1.89 times $(\mathrm{AOR}=1.89,95 \% \mathrm{CI}: 1.97$, 4.3) more likely to develop TD as compared to those taking $<200 \mathrm{mg}$. Patients taking anticholinergic medications were 4 times $(\mathrm{AOR}=4.05,95 \% \mathrm{CI}: 3.12,8.70)$ more likely to develop psychotropic medicationsinduced TD than those not using anticholinergic medications. Smoking cigarettes was $73.6 \% \quad(\mathrm{AOR}=0.264$,

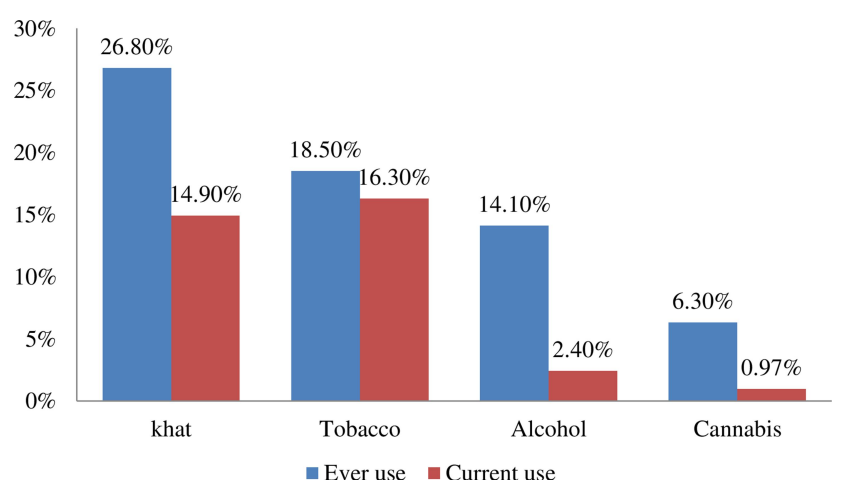

Figure 2 Type of substances used by mentally ill patients who were taking antipsychotic medications and attending follow-up treatment at JUMC, 2019.
Table 4 Signs and Symptoms and Body Parts Affected by Psychotropic Medications-Induced TD Among Mentally III Patients Attending Follow-Up Treatment at JUMC Psychiatry Clinic, 2019

\begin{tabular}{|l|l|l|}
\hline Items & Frequency (Yes) & Percent (\%) \\
\hline \multicolumn{2}{|l|}{ Questionnaire (subjective) } \\
\hline \multicolumn{2}{|l|}{ Examination: Dyskinesia Movement } \\
\hline Lingual movements & 46 & 11.2 \\
Jaw movements & 66 & 16.1 \\
Bucco-labial movements & 2 & 0.5 \\
Truncal movements & 5 & 1.2 \\
Upper extremities & 52 & 12.7 \\
Lower extremities & 2 & 0.5 \\
Other involuntary movements & 6 & 1.5 \\
\hline
\end{tabular}

95\% CI: $0.093,0.75)$ protective from developing TD compared to non-smokers (Table 5).

\section{Discussion}

\section{Prevalence of Drug-Induced Tardive Dyskinesia}

The prevalence of TD in this study was 15.4 (95\% CI: $12.0,19.0)$, which was in line with a study done in Poland $-11.9 \%,{ }^{13}$ Kenya $-11.9 \%,{ }^{18}$ and Ethiopia $11.9 \%{ }^{9}$ But it was lower than the study done in Canada - 25\%, ${ }^{11}$ Netherland - 28.4\%, ${ }^{6}$ California $63 \%,{ }^{12}$ India $-26.4 \%,{ }^{15}$ Estonia $-32.3 \%,{ }^{4}$ and South Africa $-28.4 \%^{8}$ and it may be due to the difference in clinical rating scale and exposure to only typical antipsychotics in the previous studies.

\section{Factors Associated with Tardive Dyskinesia}

During the analysis of drug-induced TD in relation to explanatory variables: Those aged $\geq 45$ years were 2.5 times more likely to develop TD compared to those aged between 15 and 29 years. This was consistent with the study done in India. ${ }^{13}$ Being female patients were significantly associated with drug-induced TD compared to male patients (AOR=3.74, 95\% CI: 1.56, 8.9). This was supported by a study done in Nigeria. ${ }^{19}$

The odds of developing TD among patients diagnosed with major depressive disorders with psychotic features were 2.3 times more likely to develop drug-induced TD as compared to those diagnosed with schizophrenia.

Those treated for $\geq 5$ years were 2.43 times $(\mathrm{AOR}=2.43$, $95 \%$ CI: $1.2,7.12$ ) more likely to develop drug-induced 
Table 5 Factors Associated with TD (Bivariate and Multivariate Logistic Regression Analysis) Among Patients Taking Antipsychotics and Attending Follow-Up Treatment at JUMC, 2019

\begin{tabular}{|c|c|c|c|c|c|}
\hline \multirow[t]{2}{*}{ Independent Variables } & \multicolumn{2}{|c|}{ Tardive Dyskinesia $(\mathrm{N}=4 \mid 0)$} & \multirow[t]{2}{*}{ COR $95 \% \mathrm{Cl}$} & \multirow[t]{2}{*}{ AOR $(95 \% \mathrm{Cl})$} & \multirow[t]{2}{*}{ P-value } \\
\hline & Yes & No & & & \\
\hline \multicolumn{6}{|l|}{ Age (years) } \\
\hline $15-29$ & 14 & $|3|$ & 1.00 & 1.00 & \\
\hline $30-44$ & 38 & 163 & $1.45(0.24,2.88)$ & $1.41(1.12,3.36)^{*}$ & 0.039 \\
\hline$\geq 45$ & 11 & 53 & $2.4(1.2,5.0)^{*}$ & $2.5 \mathrm{I}(\mathrm{I} .79,5.42)^{* *}$ & 0.005 \\
\hline \multicolumn{6}{|l|}{ Sex } \\
\hline Male & 54 & 209 & 1.00 & 1.00 & \\
\hline Female & 11 & 136 & $3.96(1.89,8.28)^{*}$ & $3.74(1.56,8.9)^{*}$ & 0.028 \\
\hline \multicolumn{6}{|l|}{ Diagnosis } \\
\hline Schizophrenia & 49 & 187 & 1.00 & 1.00 & \\
\hline MDD with psychotic features & 10 & 91 & $2.14(1.18,5.3)^{*}$ & $2.3(1.21,9.3)^{* *}$ & 0.006 \\
\hline BID with psychotic features & 6 & 67 & $2.9(1.22,7.34)^{*}$ & $1.74(0.16,6.3)$ & 0.206 \\
\hline \multicolumn{6}{|l|}{ Duration of treatment } \\
\hline$<$ l year & 3 & 34 & 1.00 & 1.00 & \\
\hline $\mathrm{I}-5$ years & 29 & 216 & $1.3(1.9,2.04)^{*}$ & $\mathrm{I} .67(0.42,5.4)$ & 0.406 \\
\hline$>5$ years & 33 & 95 & $1.27(1.02,3.57)^{*}$ & $1.37(1.16,2.86)^{*}$ & 0.015 \\
\hline \multicolumn{6}{|c|}{ Chlorpromazine equivalent dose (mg) } \\
\hline$<200$ & 11 & 136 & 1.00 & 1.00 & \\
\hline $200-600$ & 50 & 204 & $2.26(1.79,5.37)^{*}$ & $2.3(0.37,6.8)$ & 0.481 \\
\hline$>600$ & 4 & 5 & $3.2(1.84,10.8)^{*}$ & $\mathrm{I} .89(1.72,4.3)^{*}$ & 0.032 \\
\hline \multicolumn{6}{|l|}{ Anticholinergic medication use } \\
\hline Yes & 54 & 133 & $6.5(4.6,10.19)^{*}$ & $4.05(3.12,8.70)^{* * *}$ & 0.000 \\
\hline No & 9 & 214 & 1.00 & 1.00 & \\
\hline \multicolumn{6}{|l|}{ Smoking } \\
\hline Yes & 24 & 11 & $0.53(0.24,0.93)^{*}$ & $0.26(0.093,0.75)^{* * *}$ & 0.000 \\
\hline No & 39 & 336 & 1.00 & 1.00 & \\
\hline
\end{tabular}

Notes: $* C O R=$ statistically significant at $\mathrm{p}$ value $<0.25$. $* A O R=$ statistically significant at $\mathrm{p}$-value $<0.05, * *$ At $\mathrm{p}$-value $<0.0 \mathrm{I}, * * * A t \mathrm{p}$-value $<0.00 \mathrm{I}, \mathrm{Hosmer}-$ Lemeshow test $=$ 0.29 .

TD as compared to those who were treated for $<1$ year. This was supported by another study done previously. ${ }^{12,13}$

Smoking cigarette was $73.6 \%(\mathrm{AOR}=0.26,95 \% \mathrm{CI}$ : $0.093,0.75)$ protective from developing TD as compared to non-smokers. The reason might be due to that smoking is an enzyme inducer and this was supported by a study done in South Africa. ${ }^{8}$

The odds of developing drug-induced TD among patients taking anticholinergic medications were 4 times ( $\mathrm{AOR}=4.05,95 \% \mathrm{CI}: 3.12,8.70)$ as compared to those who did not use anticholinergic medications. The reason could be anticholinergic medications might be prescribed after the onset of TD and this was supported by the study done in the United Kingdom. ${ }^{26}$
Those patients receiving chlorpromazine equivalent dose $>600 \mathrm{mg}$ were 1.89 times more likely to develop to TD as compared to those receiving doses $<200 \mathrm{mg}$. This was supported by other previously conducted studies. ${ }^{8,9,13}$

\section{Limitation of the Study}

ESRS was not validated in our country.

Recall bias might occur because some reports are about the history of patients.

Physical illness and psychiatric diagnoses were reviewed from the card not investigated during the data collection period. Presence of medical condition is used for analysis rather than the type of medical illness. 


\section{Conclusions}

It is better if treatment guideline regarding the use of psychotropic medications, especially the use of antipsychotics is designed for the psychiatry case team. It is better to start with a low dose of psychotropic medications and maintain the lowest possible dose. It is better if psychoeducation is given regularly on khat use which is indigenous to the study area. It is better to look for physical illness and manage accordingly during a psychiatric assessment. Moreover, investigators would like to suggest for the Ministry of Health to be made available more Atypical Antipsychotics in our country for regular use at a low cost for patients and health facilities to reduce the burden of TD and, lastly it is good to consider the longitudinal study to establish cause and effect relationship of factors associated with TD.

\section{Data Sharing Statement}

Data generated for this study are included in the article. The data set available upon a reasonable request from the corresponding author.

\section{Ethics Approval and Consent to Participate}

Ethical approval was obtained from the Institute of Ethical Review Board of Jimma University. Written consent was taken from the participants.

\section{Acknowledgments}

The authors would like to acknowledge Jimma University, data collectors, supervisors, and study participants.

\section{Author Contributions}

All authors made substantial contributions to conception and design, acquisition of data, or analysis and interpretation of data; took part in drafting the article or revising it critically for important intellectual content; agreed to submit to the current journal; gave final approval of the version to be published; and agree to be accountable for all aspects of the work.

\section{Funding}

The financial expense for data collection was covered by Jimma University and the authors did not receive any financial support for the publication of the article.

\section{Disclosure}

The authors report no conflicts of interest for this work.

\section{References}

1. Burkhard PR. Acute and subacute drug-induced movement disorders. Parkinsonism Relat Disord. 2014;20:S108-12. doi:10.1016/S13538020(13)70027-0

2. Kirgaval RS, Revanakar S, Srirangapattna C. Prevalence of extrapyramidal side effects in patients on antipsychotics drugs at a tertiary care center. J Psychiatry. 2017;20(5):1-5.

3. Zadori D, Veres G, Levente Szalardy PK. Drug-induced movement disorders. Expert Opin Drug Saf. 2015;14(6):877-890. doi:10.1517/ 14740338.2015.1032244

4. Janno S, Holi M, Tuisku K, Wahlbeck K. Prevalence of neuroleptic-induced movement disorders in chronic schizophrenia inpatients. Am J Psychiatry. 2004;161(1):160-163. doi:10.1176/appi. ajp.161.1.160

5. Lerner V, Libov I, Kaptsan Aet al. The prevalence of neuroleptic drug-induced tardive movement sub-syndromes among schizophrenic and schizoaffective patients residing in the southern region of Israel. Isr J Psychiatry Relat Sci. 2007;1:20-28.

6. De GW, Van OJ, Van HPN. Long-stay psychiatric patients: a prospective study revealing persistent antipsychotic-induced movement disorder. PLoS One. 2011;6(10):1-6.

7. Janno S. Assessment of neuroleptic-induced movement disorders in a naturalistic schizophrenia population; 2006.

8. Patterson BD, Willows S, Swingler D, et al. Prevalence of and risk factors for tardive dyskinesia in a Xhosa population in the Eastern Cape of South Africa. Schizophr Res. 2005;76(1):89-97. doi:10.1016/j.schres.2004.10.009

9. Taye H, Awoke T, Ebrahim J. Antipsychotic medication-induced movement disorders: the case of Amanuel Specialized Mental Hospital, Addis. Am J Psychiatry Neurosci. 2014;2(5):76-82.

10. movementdisorderspolicy.org. Movement Disorders policy coalition; 2017:1-10.

11. Cortese L, Jog M, Mcauley TJ, Kotteda V, Costa G. Cautionary study. Can J Psychiatry. 2004;49(1):31-36.

12. Jack JC, Chan JJ. Cop drug-induced movement disorder us Rhann. Am J Psychiatry Neurosci. 2007;11(19):32.

13. Woźniak K, Kłoszewska I. Clinical assessment of antipsychotic-induced extrapyramidal symptoms in nursing home residents with schizophrenia. J psychiatry Clin psychol. 2016;16(1):7-14.

14. Thu T, Nguyen H, Pariente A, et al. An original pharmacoepidemiological - pharmacodynamic method: application to antipsychotic-induced movement disorders. Br J Clin Pharmacol. 2017;83(3):612-622.

15. Achalia RM, Chaturveri SKDG, Achalia RM, Chaturvedi SK, Desai G. Prevalence, and risk factors associated with tardive dyskinesia among Indian patients with schizophrenia. Asian J Psychiatr. 2014;9:31-35. doi:10.1016/j.ajp.2013.12.010

16. Divac N, Prostran M, Jakovcevski I, Cerovac N. Extrapyramidal adverse effects. Biomed Res Int. 2014;2014.

17. Osman A, Marghalani M, Turkistani IYA, Al-swaf BBS M. Neuroleptic induced tardive dyskinesia among Arab psychotic patients. East Mediterr Heal J. 2007;13:3.

18. Gatere N, Othieno CJ, Kathuku DM. Prevalence of tardive dyskinesia among psychiatric in-patients at Mathari Hospital, Nairobi. East Afr Med J. 2002;79(10):547-550.

19. Stanley PC. Prevalence and pattern of drug-induced movement disorders in University of Port Harcourt Teaching Hospital (UPTH): a 3-year Review. EC Neurol. 2016;1:36-40.

20. Okinda EK. Impact of side effects of antipsychotics on attitude and adherence to treatment among adult psychiatric outpatients at Mathari hospital in Kenya;2014.

21. Ward KM. Antipsychotic-related movement disorders: drug-induced parkinsonism vs tardive dyskinesia — key differences in pathophysiology and clinical management drug-induced parkinsonism. Neurol Ther. 2018;7(2):233-248. 
22. Strejilevich SA, Palatnik A, Avila R, Bustin J, Cassone JFS. Lack of extrapyramidal side effects predicts quality of life in outpatients treated with clozapine or typical antipsychotics. Psychiatry Res. 2005;133(2-3):277-280. doi:10.1016/j.psychres.2004.10. 009

23. Casey DE. Implications of the CATIE trial on treatment: extrapyramidal symptoms. CNS Spectr. 2006;11(S7):25-31. doi:10.1017/ S109285290002665
24. Nosé M, Barbui C, Tansella M. How often do patients with psychosis fail to adhere to treatment programs? A systematic review. Psychol Med. 2003;33(7):1149-1160. doi:10.1017/S0033291703008328

25. World Health Organization (WHO) - ASSIST V3.1: for health professionals Aust. Clinical Form; 2010.

26. Chouinard PG, Chouinard G, Margolese HC. Manual for the Extrapyramidal Symptom Rating Scale (ESRS). Schizophr Res. 2005;76(2-3):247-265. doi:10.1016/j.schres.2005.02.013

\section{Publish your work in this journal}

Clinical Pharmacology: Advances and Applications is an international, peer-reviewed, open access journal publishing original research, reports, reviews and commentaries on all areas of drug experience in humans. The manuscript management system is completely online and includes a very quick and fair peer-review system, which is all easy to use. Visit http://www.dovepress.com/testimonials.php to read real quotes from published authors.

Submit your manuscript here: https://www.dovepress.com/clinical-pharmacology-advances-and-applications-journal 